\title{
Modelling lead-rubber seismic isolation bearings using the unified mechanics theory
}

\author{
Hernán Martín Hernández Morales*a,b iD \\ ${ }^{a}$ State University of New York at Buffalo, Department of Civil, Structural and Environmental Engineering, \\ $N Y, U S A$ \\ ${ }^{b}$ National University of Engineering, Department of Civil Engineering, Lima, Peru
}

\begin{abstract}
Lead-rubber seismic isolation bearings (LRB) have been installed in a number of essential and critical structures, like hospitals, universities and bridges, in order to provide them with period lengthening and the capacity of dissipating a considerable amount of energy to mitigate the effects of strong ground motions. Therefore, studying the damage mechanics of this kind of devices is fundamental to understand and accurately describe their thermo-mechanical behavior, so that seismically isolated structures can be designed more safely. Hitherto, the hysteretic behavior of LRB has been modeled using 1) Newtonian mechanics and empirical curve fitting degradation functions, or 2) heat conduction theories and idealized bilinear curves which include degradation effects. The reason for using models that are essentially phenomenological or that contain some adjusted parameters is the fact that Newton's universal laws of motion lack the term to account for degradation and energy loss of a system. In this paper, the Unified Mechanics Theory - which integrates laws of Thermodynamics and Newtonian mechanics - is used to model the force-displacement response of LRB. Indeed, there is no need for curve fitting techniques to describe their damage behavior because degradation is calculated at every point using entropy generation along the Thermodynamics State Index (TSI) axis. A finite element model of a lead-rubber bearing was constructed in ABAQUS, where a user material subroutine UMAT was implemented to define the Unified Mechanics Theory equations and the viscoplastic constitutive model for lead. Finite element analysis results were compared with experimental test data.
\end{abstract}

\section{Keywords}

Lead-rubber bearings; Seismic isolation; Unified Mechanics Theory; Damage mechanics; Entropy; Thermodynamics

Received: 27 August 2021; Accepted: 20 December 2021

ISSN: 2630-5763 (online) C 2021 Golden Light Publishing All rights reserved.

\section{Introduction}

Since the pioneering work of W. H. Robinson [1], it is well-known that the hysteretic behavior of lead rubber bearings can be simply modelled as a bilinear curve, where the initial elastic stiffness that depends mainly on lead - is approximately 10 times the post yield stiffness, which is governed by rubber. Consequently, LRB has been included in general and specialized dynamic analysis computer programs, such as SAP 2000 [2] and 3D-BASIS [3], respectively.

\footnotetext{
* Corresponding author

Email: hernanma@buffalo.edu
} 
Phenomenological models have been proposed in order to represent LRB behavior more realistically; i.e. to account for damage. For example, Kikuchi and Aiken model [4] can capture the degradation of the stiffness associated with load history, recognizing it as a complex phenomenon. Constantinou et al $[5,6]$ studied the effects of load history too, but the major contribution of their research is modeling strength degradation through lead core heating effects without performing lab tests to calibrate the model $[5,6,7]$. However, the dynamic equations that complement the heatconduction based formulation include the bilinear hysteretic model suggested by Robinson [1].

Given its effectiveness to model damage suffered by lead rubber bearings due to temperature increase, other heat-conduction representations integrated with phenomenological or adjusted models have been created. For instance, Wake et al [8] combine the Kikuchi and Aiken model [4] and the finite volume method applied to heatconduction analysis in order to describe strength degradation in LRB during long-duration earthquakes. Nevertheless, as stated at the end of [4], "Further work to develop analytical models of elastomeric bearings based upon fundamental principles of computational continuum mechanics is required". Therefore, it is fundamental to highlight the need for applying continuum damage mechanics to better describe the hysteretic behavior of LRB.

In this paper, the Unified Mechanics Theory [933], which was originally developed for microelectronic solder joints in multilayered electronics packages, was used to model the hysteretic thermo-mechanical behavior of a leadcore rubber seismic isolation bearing. Finite element analysis results were compared with lab test data taken from [5,6]. This is the first attempt to model the mechanical behavior of LRB by means of applying the Unified Mechanics Theory [34].

A brief explanation of the complex behavior of lead and why it is used in elastomeric bearings is given in section 2. Likewise, the fundamentals of the Unified Mechanics Theory and its application to model lead are expounded in this part. In section 3, the finite element model of a LRB is described. Finally, the results obtained from ABAQUS simulations are compared with test data.

\section{Simulating the mechanical behavior of lead}

Lead-rubber isolation bearings are assumed to have the idealized hysteretic behavior shown in Fig. 1. The principal parameters are the characteristic strength $Q_{d}$ - which is similar to the shear yield force $F_{Y}-$ and the post-elastic stiffness $K_{d}$. The value of the elastic stiffness $K_{e l}$ is expected to be close to $10 K_{d}$ [1], while the yield displacement $Y$ varies from 12 to $25 \mathrm{~mm}$.

The energy dissipation capacity of LRB is closely related to the characteristic strength, which is dependent on the cross section of the lead core, its confinement, and its rate of shear strain deformation as well as the history of loading in terms of the number, amplitude and frequency of high-speed seismic motion cycles [6]. Thus, the mechanical behavior of lead strongly determines the main characteristics of the hysteretic behavior of lead-rubber bearings.

The mechanical properties of lead depend on multiple factors, such as crystal structure, grain size, degree of plastic deformation, temperature, purity, and strain rate. Lead has an A1-type FaceCentered Cubic (FCC) crystal structure, so that it remains ductile even at very low temperatures [6]. Although other metals like aluminum and copper have the same A1 lattice, plastically deforming lead at $20^{\circ} \mathrm{C}$ (or even at $-4^{\circ} \mathrm{C}$ ) is equivalent to plastically deforming those at $150^{\circ} \mathrm{C}$ and $200^{\circ} \mathrm{C}$, respectively.

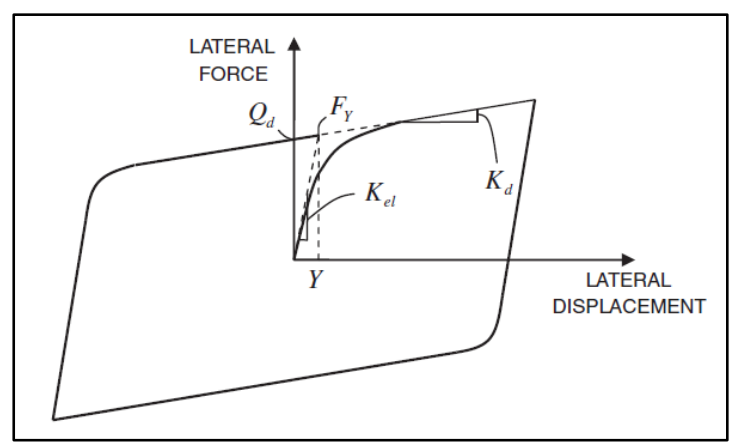

Fig. 1. Idealized force-displacement response of a leadrubber bearing [7] 
Because these temperatures represent the recrystallization temperature in each case. For steel, which constitutes plates and shims of LRB, and has an A2-type crystal structure, recrystallization temperature is even greater: $450^{\circ} \mathrm{C}$ [35].

Since the recrystallization temperature of lead is below room temperature, any deformation at or above it is "hot work", in which the processes of recovery, recrystallization and grain growth occur simultaneously [1,35]. Deformation of polycrystalline metals results in elongation of the grains and a considerable increase in the number of defects (dislocations and vacancies) in each grain. Thus, during recovery, the stored energy of the deformed grains is reduced by the dislocations moving to form lower energy configurations, and by the annihilation of vacancies. Then, recrystallization occurs when deformed grains are replaced by small, new, undeformed grains that nucleate among the deformed ones and grow until them have been totally consumed. Further grain growth happens when some of the new grains become larger at the expense of others $[6,35]$. Therefore, all these mechanisms make lead more ductile even at low temperatures.

It is important to highlight that the greater the percentage of plastic deformation is, the lower the recrystallization temperature is. Thus, high plastic deformation and high temperatures facilitate recrystallization. Likewise, the beginning of recrystallization shifts to lower temperatures and less amount of plastic deformation on increasing the degree of purity of lead. In LRB, lead is of high purity, i.e., more than $99.9 \%$. Moreover, the tensile strength of lead - and so the shear strength - drops with a decreasing strain rate because there is enough time for recrystallization to take place in case of low deformation rates, and it contributes to the inhibition of strain hardening.

As a conclusion, the mechanical properties of lead are continuously restored - not totally but largely - by the interrelated and simultaneous processes of recovery, recrystallization, and grain growth, which makes lead an ideal material to be used in seismic isolators due to its good fatigue properties during cycling at plastic strains and high energy dissipation capacity, additionally to its relatively low shear yield stress of 10 to $12 \mathrm{MPa}$, and its elastic-viscoplastic behavior.

\subsection{Unified mechanics theory}

The Unified Mechanics Theory (UMT) unites laws of thermodynamics and Newton's universal laws of motion. This theory also modifies Newtonian space time coordinate system with the addition of the Thermodynamics State Index (TSI) axis, which goes between zero and one (see Fig. 2). As a result of the new axis, derivative of displacement with respect to entropy is not zero as in classical Newtonian mechanics [9].

Degradation evolution occurring in a system, in this case LRB, follows the laws of thermodynamics. According to the second law of thermodynamics, entropy production rate becomes minimum when entropy is maximum. When a closed system can no longer generate entropy for a pre-defined mechanism, it is considered failed (or dead). Degradation happens due to irreversible entropy generation, which is always a non-negative quantity.

While Unified Mechanics Theory is not new, however, this is the first application to simulate the hysteretic behavior of LRB. Unified Mechanics Theory laws can be summarized in their simplified form as follows [9]:

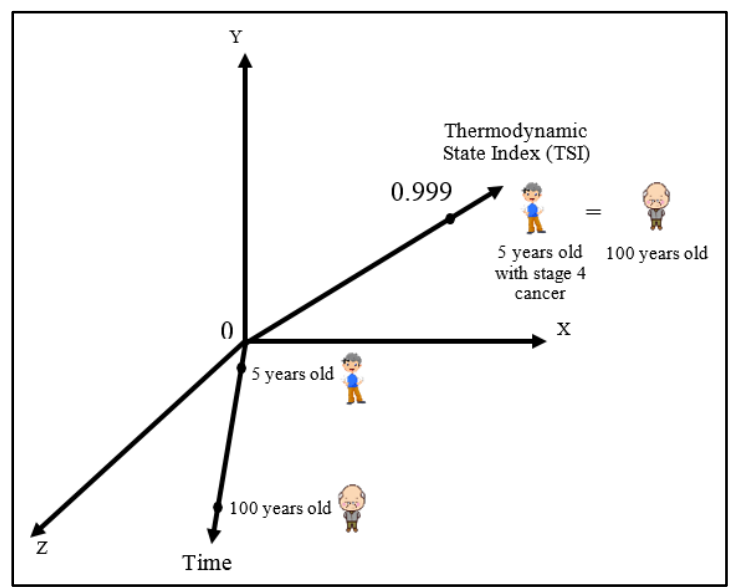

Fig. 2. Dimensional Coordinate System in Unified Mechanics Theory $[9,10]$ 
$\left(1-\Phi\left(\dot{s}_{f}\right)\right) F d t=d(m v)$

$F=k_{u} u\left(1-\Phi\left(\dot{s}_{k}\right)\right)$

where: $F=$ force, $m=$ mass, $v=$ velocity, $k_{u}=$ stiffness, $u=$ displacement, $\Phi=$ Thermodynamic State Index, which is the normalized form of the second law of thermodynamics, $\dot{s}_{f}=$ entropy (per unit mass) generation responsible for the loss in momentum, and $\dot{s}_{k}=$ entropy (per unit mass) generation responsible for degradation of the stiffness. TSI is defined by the thermodynamic fundamental equation of the material which provides the entropy (per unit mass) generation rate $(\dot{s})$ in the system for all active micro mechanisms. Value of TSI starts at zero and finally reaches one. In fact, Eqs. (1a) and (1b) are nothing but the combination of second and third universal laws of motion of Newton and the second law of thermodynamics.

In this study, it is assumed that only lead provides entropy production in LRB. Of course, there is entropy generation in rubber layers and steel shims and plates. However, only lead experiences plastic deformation. Therefore, as a first iteration, it is considered that entropy production in rubber and steel is negligible compared to that in lead.

\subsubsection{Entropy balance}

Entropy is a measure of how much energy is unavailable to do work as a result of loss and dissipation during a process in a closed system, and it is associated with a change in temperature [36]. Therefore, entropy can be created - in contrast to energy - and can only increase. The variation of total entropy $d S$ at a point may be written as the sum of two terms for a closed-isolated system as follows [37]:

$d S=d S_{e}+d S_{i}$

where: $S_{e}=$ entropy gained from the transfer of heat from external sources across the boundary of the system, $S_{i}=$ entropy produced inside the system. The second law of Thermodynamics states that $d S_{i} \geq 0$, while $d S_{e}$ can be positive, zero or negative.

\subsubsection{Degradation evolution function}

Degradation is the progressive deterioration that occurs in materials prior to failure. In Unified Mechanics Theory, degradation evolution function is based on the second law of thermodynamics and statistical physics, so that there is a relationship between irreversible entropy generation and degradation [9,10,37]. During the cumulative degradation process, the internal entropy production, which is a measure of disorder of a system, must increase. Thus, it can be used for mapping the evolution of degradation onto TSI axis. Thermodynamic State Index is given by [9, 10]:

$\Phi=\Phi_{c r}\left[1-e^{-\frac{m_{s}}{\mathrm{R}}\left(s-s_{0}\right)}\right]$

where: $\Phi_{c r}=$ critical value of TSI (a user defined value), $m_{s}=$ molar mass, $\mathrm{R}=$ universal gas constant, $s=$ entropy per unit mass at a point at time $t$, and $s_{o}=$ entropy per unit mass at a point at the beginning of the process (it can be taken as zero for the reference state). The change in entropy per unit mass $\left(s-s_{0}\right)$ at a point can be calculated using the fundamental equation for a thermo-mechanical loading [10,28]:

$$
\begin{aligned}
\Delta s=s-s_{0}=\int_{t_{0}}^{t} & \frac{\sigma: \dot{\varepsilon}^{P}}{T \rho} d t \\
& +\int_{t}^{t_{0}} \frac{\lambda}{T^{2} \rho}|\operatorname{grad} T|^{2} d t \\
& +\int_{t_{0}}^{t} \frac{r}{T} d t
\end{aligned}
$$

where: $\sigma=$ stress tensor, $\dot{\varepsilon}^{p}=$ plastic strain rate vector, $T=$ absolute temperature in Kelvin, $\rho=$ density, $\lambda=$ thermal conductivity, and $r=$ distributed internal heat source per unit mass. Given that $\Delta s$ is a non-negative quantity, $\Phi \geq 0$ is always satisfied. Thermodynamic State Index $(\mathrm{TSI}=\Phi)$ is initially assumed to be zero, and it reaches the value of one when entropy generation rate is zero.

In this fundamental equation, it is assumed that entropy generation is limited to plastic work and internal heat generation under cyclic loading. In this 
study, for simplicity, only the first term of Eq. (4) was taken into account to calculate $\Delta s$. Therefore, certain amount of error is expected.

It must be emphasized that only irreversible entropy generation $S_{i}$ should be used as a basis for the systematic description of damage processes because $S_{e}$ has no influence in the degradation of materials [10, 37].

\subsection{Degradation coupled viscoplasticity material model}

Unified Mechanics Theory provides a framework for degradation of material properties according to laws of Thermodynamics. Thus, in accordance with the strain equivalence principle and Hooke's law, the elasticity constitutive relationship for lead, assuming small strains, can be written as:

$d \sigma=(1-\Phi) C_{0}\left(d \varepsilon-d \varepsilon^{p}-d \varepsilon^{T}\right)$

where: $C_{0}=$ initial stiffness matrix, $d \varepsilon=$ total strain increment vector, $d \varepsilon^{p}=$ inelastic strain increment vector, and $d \varepsilon^{T}=$ thermal strain increment vector.

2.2.1. Von Mises yield surface with isotropic and kinematic hardening

Knowing that lead has an elastic-viscoplastic behavior, Von Mises type yield function is used to separate elastic and inelastic response [25]:

$$
\begin{aligned}
F_{S}=\left\|S_{\sigma}-X\right\|- & \sqrt{\frac{2}{3}} \sigma_{y} \\
& =\sqrt{\left(S_{\sigma}-X\right):\left(S_{\sigma}-X\right)} \\
& -\sqrt{\frac{2}{3}}\left(\sigma_{y 0}+R_{\sigma}\right)
\end{aligned}
$$

where: $F_{S}=$ yield surface separating the elastic from the inelastic response, $S_{\sigma}=$ deviatoric component of the total stress tensor $\sigma, X=$ deviatoric part of the back stress tensor, $\sigma_{y 0}=$ initial size of the yield surface, $R_{\sigma}=$ isoparametric hardening function giving evolution of the size of the yield surface. $R_{\sigma}$ and $\dot{X}$ can be calculated by $[25,38]$ :

$R_{\sigma}=R_{\infty}\left(1-e^{-c \alpha}\right)$
$\dot{X}=\frac{2}{3} c_{1} \dot{\boldsymbol{\varepsilon}}^{P}-c_{2} X \dot{\alpha}$

where: $R_{\infty}=$ isotropic hardening saturation value, $c$ $=$ isotropic hardening material parameter, $c_{1}=X_{\infty}$ $=$ non-linear kinematic hardening saturation value, $c_{2}=$ nonlinear kinematic hardening material parameter, $\dot{\alpha}=$ equivalent plastic strain rate, which is given by:

$\dot{\alpha}=\sqrt{\frac{2}{3}\left(\dot{\boldsymbol{\varepsilon}}^{p} \dot{\boldsymbol{\varepsilon}}^{p}\right)}$

\subsubsection{Flow rule and consistency parameter}

The evolution of the plastic strain vector is represented by a general flow rule of the form:

$\dot{\varepsilon}^{P}=\dot{\gamma} \frac{\partial F_{s}}{\partial \sigma}=\dot{\gamma} \hat{n}$

where: $\hat{n}=$ vector normal to the yield surface that specifies the direction of plastic flow, $\dot{\gamma}=$ rate of plastic flow. For a rate dependent material model, $\dot{\gamma}$ can be calculated by:

$\dot{\gamma}=\frac{\left\langle\phi\left(F_{s}\right)\right\rangle}{\eta}$

where: $\eta=$ viscosity material parameter, \langle\rangle$=$ Macaulay brackets, $\phi\left(F_{s}\right)=$ material specific function defining the character of the viscoplastic flow.

\subsubsection{Viscoplastic creep law}

The following creep law [21, 25, 30, 39] was used for lead:

$\dot{\varepsilon}^{P}=\frac{A D_{0} E b}{\mathrm{k} T}\left(\frac{\left\langle F_{s}\right\rangle}{E}\right)^{n}\left(\frac{b}{d}\right)^{p} e^{-\frac{Q}{\mathrm{RT}}} \frac{\partial F_{s}}{\partial \sigma}$

where: $A=$ temperature and rate dependent dimensionless material parameter, $D_{0}=$ frequency factor, $E=$ temperature dependent Young's modulus, $b=$ characteristic length of crystal dislocation (magnitude of Burger's vector), $\mathrm{k}=$ Boltzmann's constant, $n=$ stress exponent for viscoplastic deformation rate, $d=$ average grain size, $p=$ grain size exponent, $Q=$ creep activation energy. Then, from equations (10), (11) and (12): 
$\left\langle\phi\left(F_{s}\right)\right\rangle=\left\langle F_{s}\right\rangle^{n}$

$\eta=\frac{\mathrm{k} T}{A D_{0} E^{1-n} b}\left(\frac{d}{b}\right)^{p} e^{\frac{Q}{\mathrm{RT}}}$

The material model presented in this section was implemented in the general-purpose finite element program ABAQUS using UMAT subroutine option to model lead.

\section{Finite element model of a lead-rubber bearing}

The lead-rubber bearing analyzed herein is shown in Fig. 3. It is a large-scale LRB which was designed for a bridge application [5,6]. The leadcore area is $0.025 \mathrm{~m}^{2}\left(38.5 \mathrm{in}^{2}\right)$ and the bonded rubber area is $0.650 \mathrm{~m}^{2}\left(1007.9 \mathrm{in}^{2}\right)$. Given that each rubber layer has a thickness of $0.01 \mathrm{~m}$ (0.4 in), the shape factor (loaded area / area free to bulge) is around 22, value associated with high vertical stiffness and adequate horizontal flexibility [40].

The bearing was tested by applying a constant vertical load of $3783 \mathrm{kN}$ (850.5 kip) and a sinusoidal horizontal displacement with a period $T=2 s$ and amplitud $D_{M}=0.305 \mathrm{~m}$ (12 in), which leads to a peak velocity $v_{\text {max }}=0.958 \mathrm{~m} / \mathrm{s}(37.7$ in $/ \mathrm{s}$ ) and a maximum shear strain $\gamma_{\max }=120 \%$ $[5,6]$. This experiment was simulated in ABAQUS.

\subsection{Properties of materials}

Table 1 presents several properties of lead deemed in the finite element analysis of the LRB.

Some mechanical properties of lead were obtained from experimental data provided by $[5,6]$. For example, the Young's modulus $E=0.42 \mathrm{GPa}$ at $20^{\circ} \mathrm{C}$ (Fig. 4) was measured by means of a monotonic tensile test of a high-purity lead specimen at high strain rate $(0.25 / \mathrm{s})$.

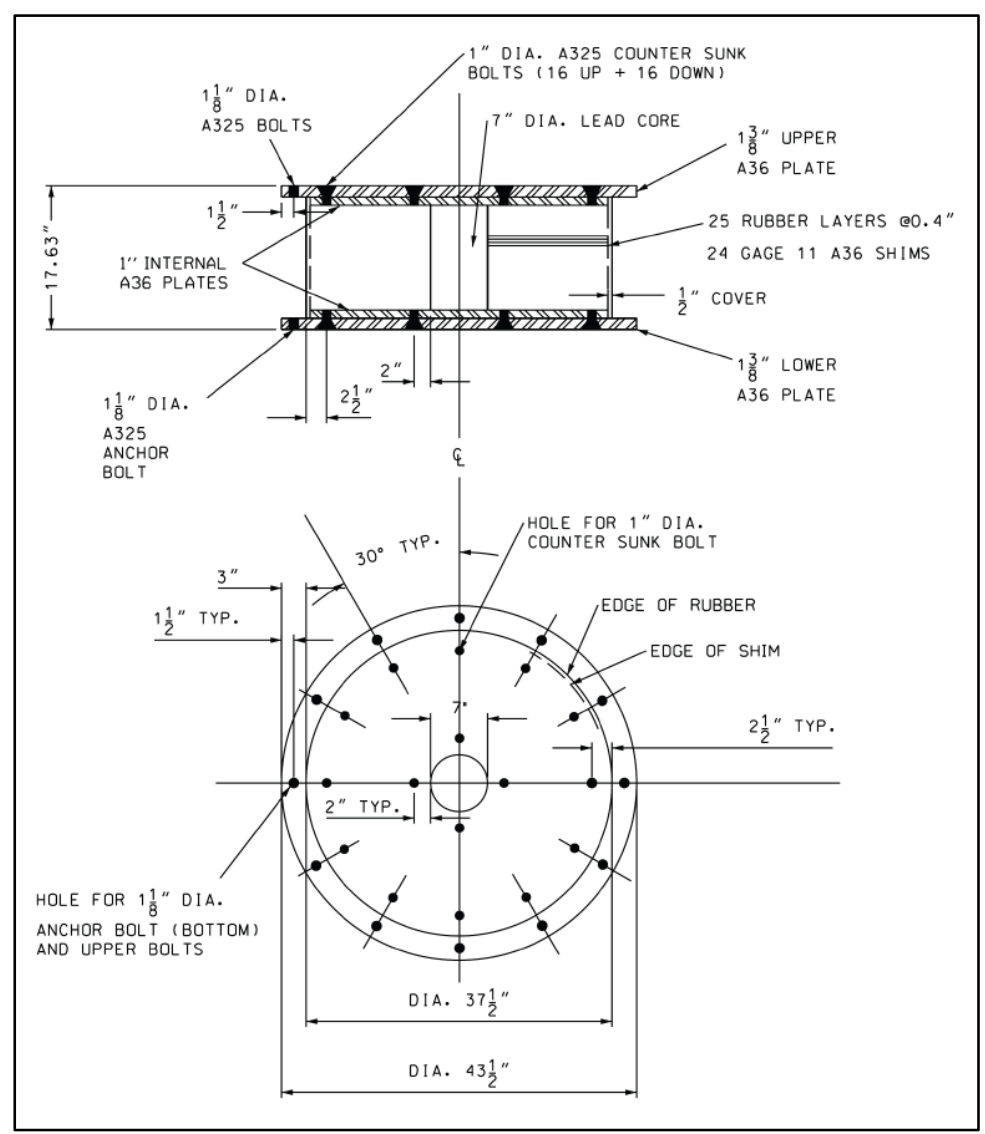

Fig. 3. Geometry of the LRB seismic isolator under study $[5,6]$ 


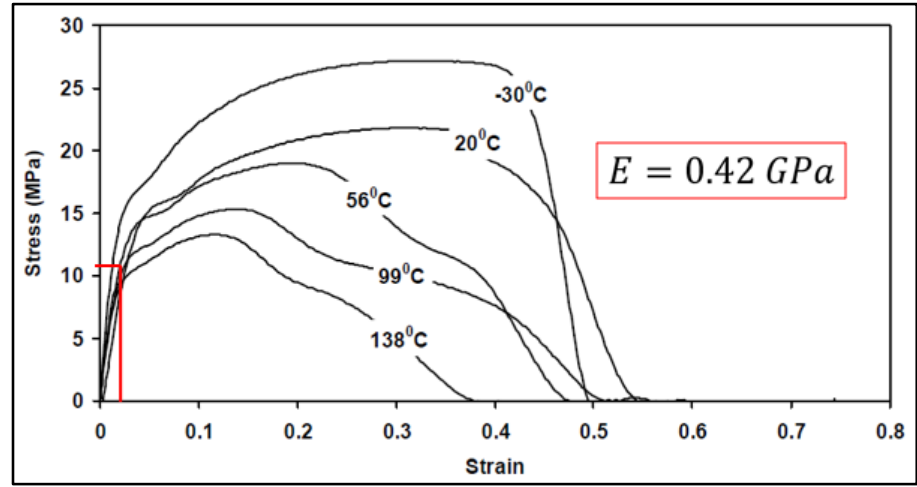

Fig. 4. Determination of the Young's modulus $E$ of high-purity lead at $20^{\circ} \mathrm{C}[6]$

Although this value of $E$ does not belong to the commonly accepted range from 14.5 to $20 \mathrm{GPa}$ [41], its validity can be easily verified through calculating the associated shear modulus and multiplying it by the shear strain obtained assuming an average value of the yield displacement $Y$ (Fig. $1)$. The calculated shear yield stress $\sigma_{y}$ is around 11.6 $\mathrm{MPa}$, the initial value considered for the analysis [5]. Values of $E$ and $\sigma_{y}$ at $20^{\circ} \mathrm{C}$ can be obtained by replacing $\mathrm{T}=293.15 \mathrm{~K}$ in the respective formulas of Table 1 .

Table 1. Thermo-mechanical properties of lead

\begin{tabular}{|c|c|c|c|}
\hline Property & Symbol & Value & Unit \\
\hline Young's modulus & $\mathrm{E}$ & $1050-2.14 \mathrm{~T}$ & $\mathrm{MPa}$ \\
\hline Poisson's ratio & v & 0.44 & \\
\hline Shear yield stress & $\sigma_{\mathrm{y}}$ & $23-0.039 \mathrm{~T}$ & $\mathrm{MPa}$ \\
\hline $\begin{array}{l}\text { Kinematic } \\
\text { hardening } \\
\text { saturation value }\end{array}$ & $\mathrm{X}_{\infty}$ & 510 & $\mathrm{MPa}$ \\
\hline $\begin{array}{l}\text { Isotropic hardening } \\
\text { saturation value }\end{array}$ & $\mathrm{R}_{\infty}$ & 9.37-0.019T & $\mathrm{MPa}$ \\
\hline Density & $\rho$ & 11.3 & $\mathrm{t} / \mathrm{m}^{3}$ \\
\hline Molar mass & $\mathrm{m}_{\mathrm{s}}$ & $2.07 \mathrm{E}-04$ & $\mathrm{t} / \mathrm{mol}$ \\
\hline Stress exponent & $\mathrm{n}$ & 1.67 & \\
\hline $\begin{array}{l}\text { Magnitude of } \\
\text { Burger's vector }\end{array}$ & $\mathrm{b}$ & $3.18 \mathrm{E}-10$ & $\mathrm{~m}$ \\
\hline Average grain size & $\mathrm{d}$ & $1.06 \mathrm{E}-05$ & $\mathrm{~m}$ \\
\hline Grain size exponent & $\mathrm{p}$ & 3.34 & \\
\hline $\begin{array}{l}\text { Creep activation } \\
\text { energy }\end{array}$ & Q & 44.7 & $\mathrm{KJ} / \mathrm{mol}$ \\
\hline
\end{tabular}

*T = Absolute Temperature $(K)$
However, the majority of lead material properties needed for the viscoplastic constitutive model were assumed to be similar to eutectic $63 \mathrm{Sn} / 37 \mathrm{~Pb}$ solder alloy [25]. This approximation was made because viscoplastic material properties of pure lead were not available. In order to verify the adequacy of such assumption, the monotonic test previously referred to was simulated in ABAQUS. Probable values of $R_{\infty}$ and $X_{\infty}$ parameters for high-purity lead were obtained (see Fig. 5).

Therefore, it was necessary to determine twenty-five material properties to simulate the real behavior of lead, as shown in Fig. 6 .

Rubber and steel are the other main material components of the LRB. The first is a nearly incompressible polymer with Poisson's ratio $v$ very close to 0.5 (0.4998). Its shear modulus $G$ can be approximated to be $0.7 \mathrm{MPa}$ for strains from 50 to $200 \%$. Thus, the bulk modulus $K$ is near $2000 \mathrm{MPa}$, a value used in the design of elastomeric bearings [5]. In this case, a neo-Hookean material was selected to model rubber due to its simplicity - it is only necessary to know the values of bulk and shear modulus - and the lack of test data. Properties of $v=0.495$, the ABAQUS's maximum allowable value, and $G=0.7 \mathrm{MPa}$ were assigned. Moreover, steel was modeled as a linear-elastic material. 


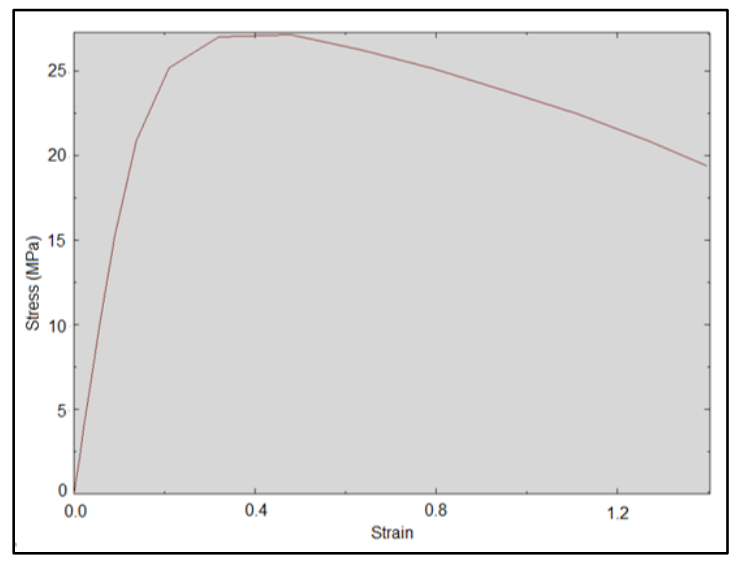

Fig. 5. Simulation in ABAQUS of the monotonic tensile test $\left(20^{\circ} \mathrm{C}\right)$ of Fig. 4

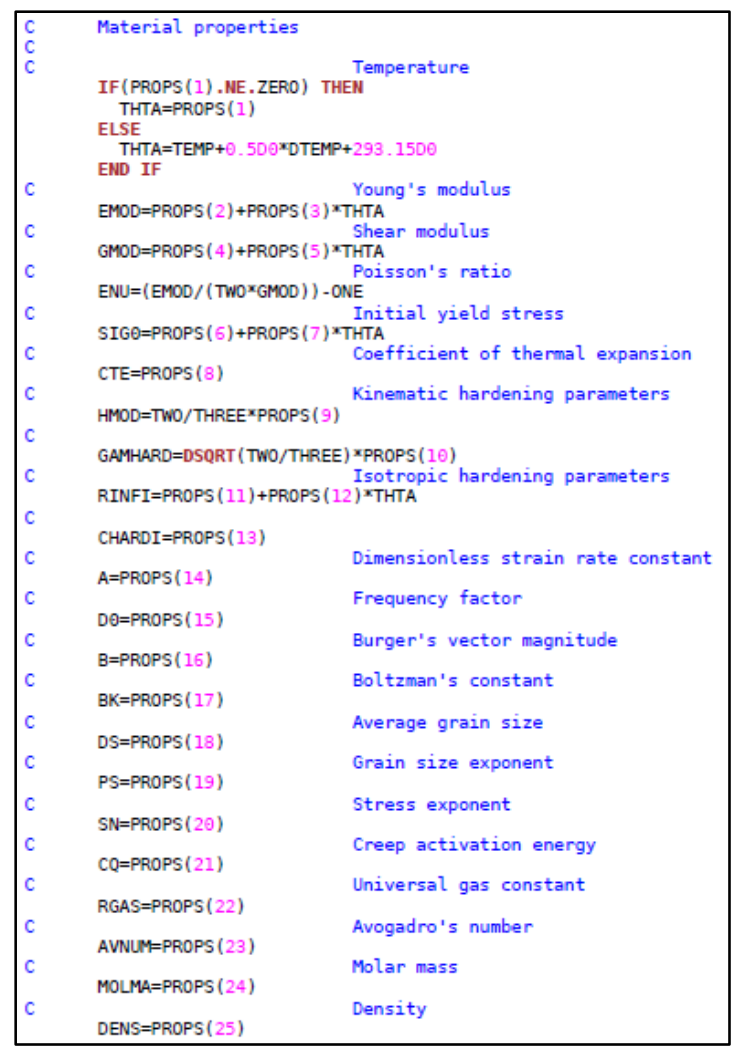

Fig. 6. Part of UMAT subroutine to define lead material properties

\subsection{Analysis using ABAQUS and comparison with lab test data}

Fig. 7 shows the mathematical model used to simulate the hysteretic behavior of the LRB under study.
In Fig. 7(a), internal and external upper and bottom plates, rubber layers, steel shims and the lead core of the isolator are shown. In Fig. 7(b), the FE mesh of the lead rubber bearing model is depicted. The mesh has 217805 nodes and 103783 elements: 1007 linear wedge elements of type C3D6 for the lead core and 102776 quadratic tetrahedral elements of type C3D10 for the other parts of the LRB (see Fig. 8).

It is important to remember that second and third term of the thermodynamic fundamental equation (4) were not considered in this analysis for simplicity. Results of the finite element heat transfer analysis of the isolator [6], which are shown in Fig. 9, were imposed on the material properties.

Fig. 10 shows the deformed shape of the LRB and the distribution of shear stress along the height of the lead core during the dynamic analysis in ABAQUS. Fig. 11 presents the theoretical and experimental hysteresis loops of the lead-rubber bearing under study. Only the first three loops are computed by means of the Unified Mechanics Theory because the amount of energy dissipated by an isolator during a strong ground motion is approximately the same to that for 3 cycles at the maximum displacement $D_{M}$ [43]. This curve demonstrates that Unified Mechanics Theory can simulate the hysteretic behavior of LRB particularly, the second loop (see Fig. 12) although the match is not perfect. For example, the ascending branch of the first loop follows a different path than the one from laboratory testing. Nevertheless, it should be noted the unexpected sinusoidal shape at the beginning of the lab test loop, which was imposed by the test machine. Another limitation of the theoretical model is that the initial part of the loops at reversal of motion could not be captured well, as shown more clearly in Fig. 12. However, that particular behavior probably could only be replicated by applying phenomenological adjustments, as indicated in other research works [7].

The plot of the average Thermodynamic State Index vs. number of cycles is shown in Fig. 13. 


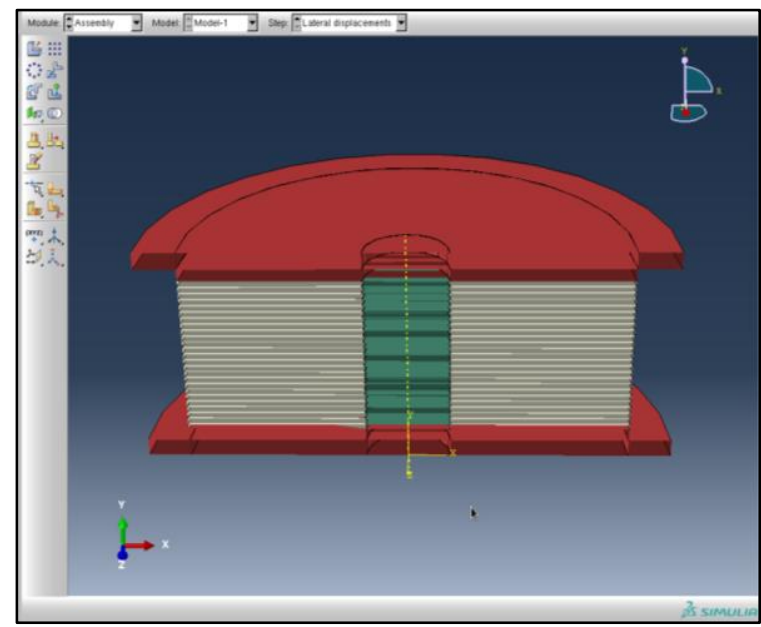

(a)

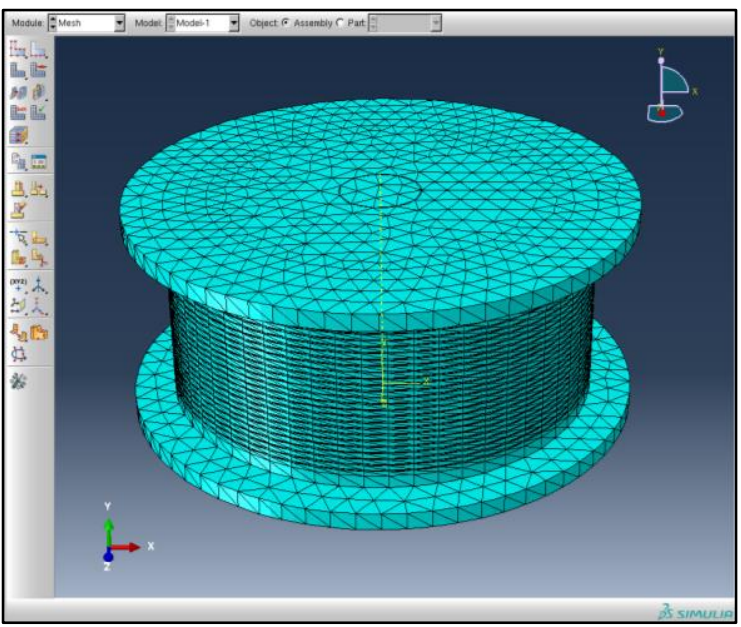

(b)

Fig. 7. (a) LRB cross section and (b) mesh for finite element analysis in ABAQUS

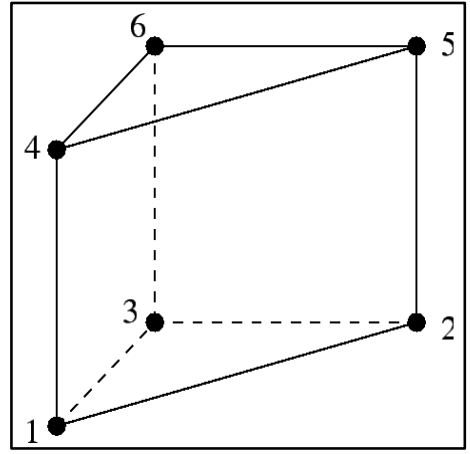

(a)

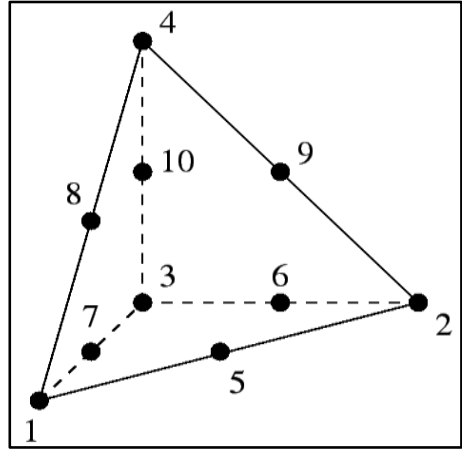

(b)

Fig. 8. (a) 6-node wedge and (b) 10-node tetrahedral elements in ABAQUS [42]

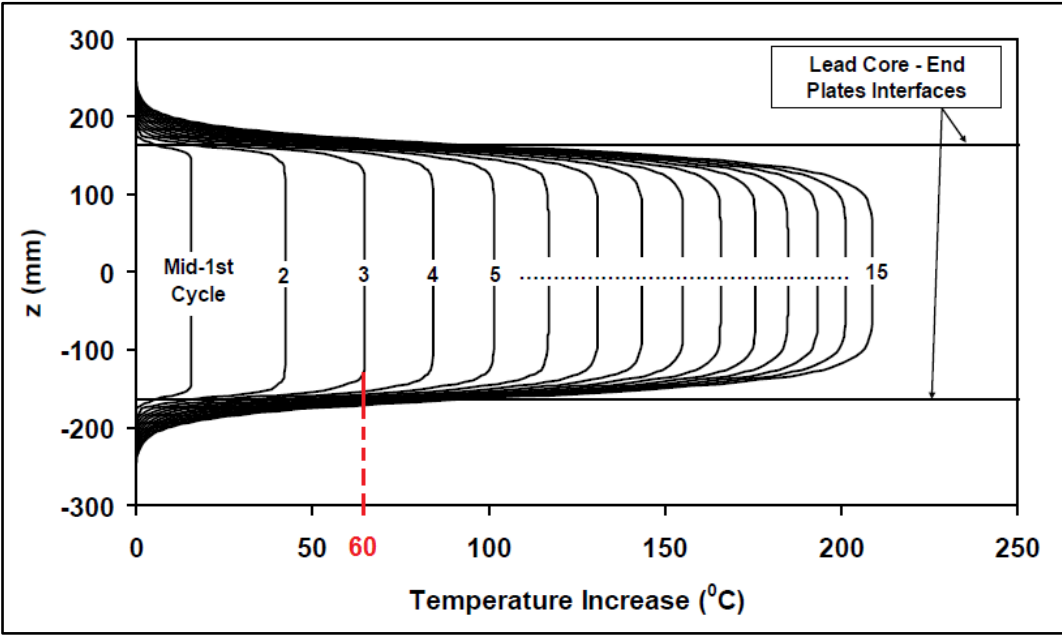

Fig. 9. Vertical distribution of temperature increment at the center of the lead core as a function of the number of cycles [6] 


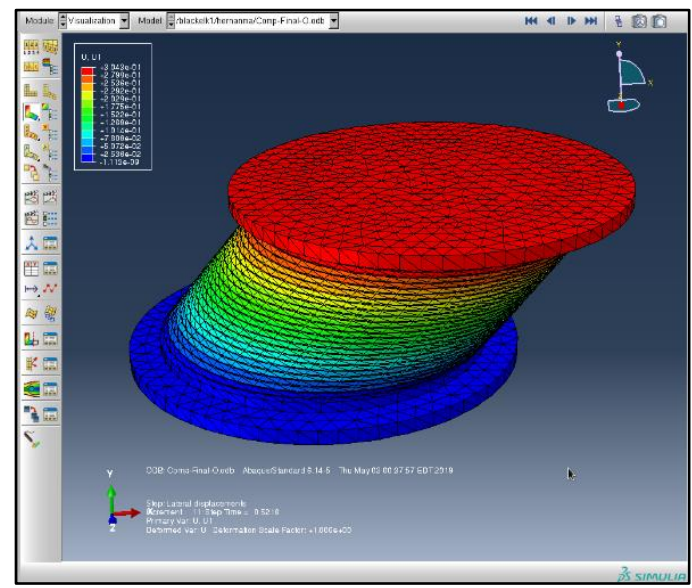

(a)

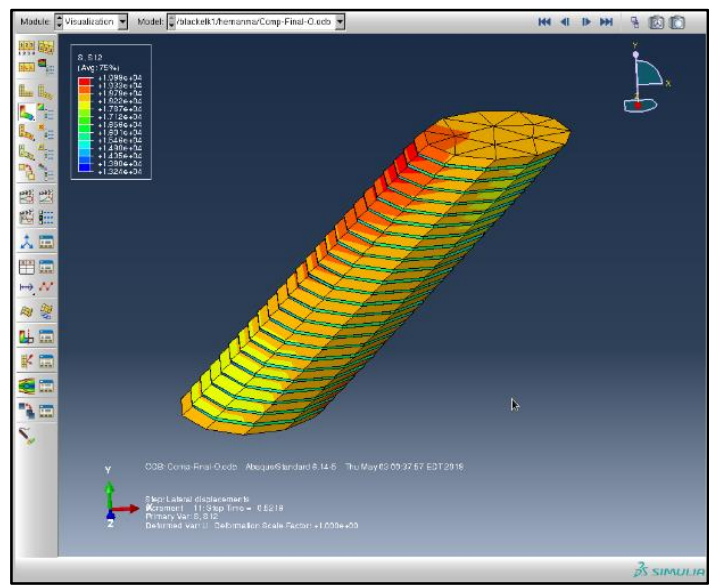

(b)

Fig. 10. (a) LRB reaching the maximum displacement $D_{M}=0.305 \mathrm{~m}$, and (b) the respective shear stress distribution in the lead core

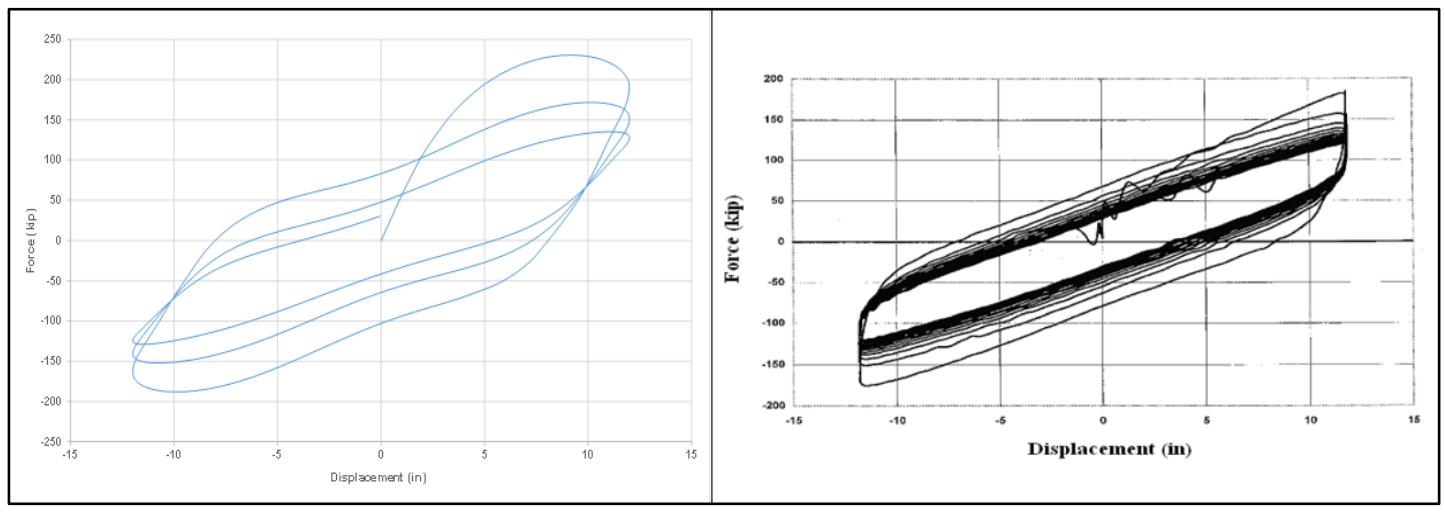

(a)

(b)

Fig. 11. Force-displacement loops of the LRB from (a) Unified Mechanics Theory and (b) lab test $[5,6]$

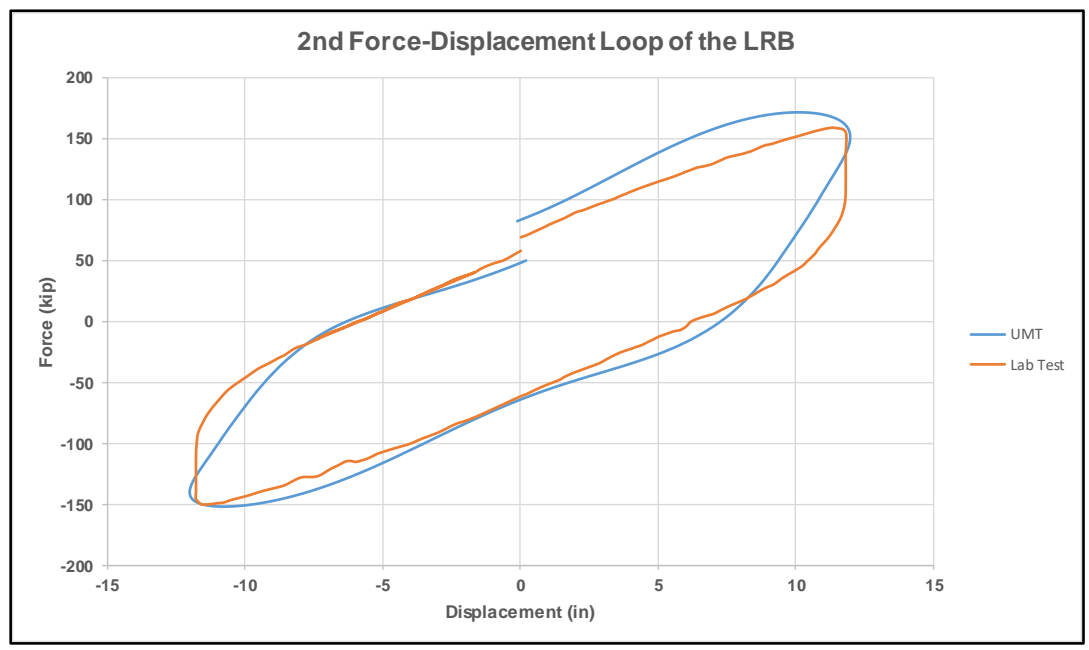

Fig. 12. Comparison of the $2^{\text {nd }}$ force-displacement hysteresis loop obtained from Unified Mechanics Theory and lab test $[5,6]$ 


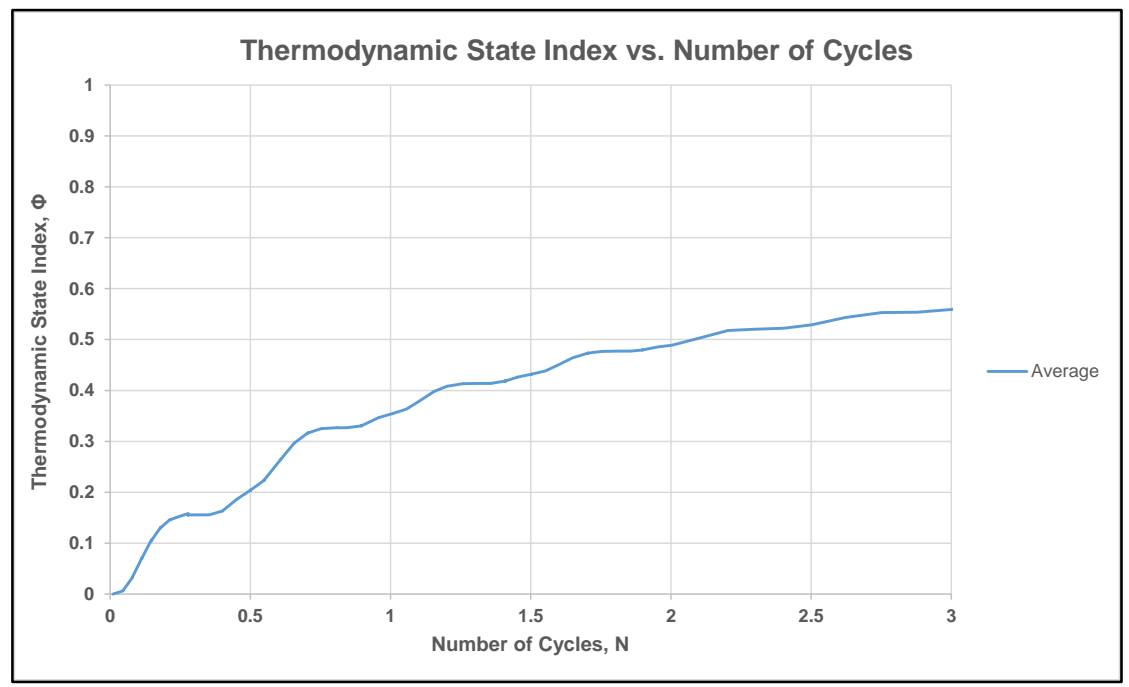

Fig. 13. Variation of the Thermodynamic State Index throughout the simulation

Although the value of TSI parameter is somehow overestimated during the first loop, it should be noted that it increases from 0.35 to 0.48 during the second one, which represents a degradation in LRB stiffness and strength of around $35 \%$. This value is approximately the same to the percentage decrease of the characteristic strength for that loop (see Fig. 12).

Table 2. Comparison of the energy dissipated per cycle (EDC) obtained from Unified Mechanics Theory and test data

\begin{tabular}{cccc}
\hline \multirow{2}{*}{ Cycle } & \multicolumn{2}{c}{ EDC $(\mathrm{kN}-\mathrm{m})$} & \multirow{2}{*}{ error $(\%)$} \\
\cline { 2 - 3 } & Test & Model & \\
\hline 1 & 375.0 & 489.3 & 30.5 \\
2 & $\mathbf{3 0 5 . 0}$ & $\mathbf{3 2 9 . 1}$ & $\mathbf{7 . 9}$ \\
3 & 260.0 & 207.1 & -20.4 \\
\hline
\end{tabular}

Table 3. Comparison of the effective stiffness $\left(K_{e f f}\right)$ obtained from Unified Mechanics Theory and test data

\begin{tabular}{cccc}
\hline \multirow{2}{*}{ Cycle } & \multicolumn{2}{c}{$K_{\text {eff }}(\mathrm{kN} / \mathrm{m})$} & \multirow{2}{*}{ error $(\%)$} \\
\cline { 2 - 3 } & Test & Model & \\
\hline 1 & 2583.0 & 2595.5 & 0.5 \\
2 & $\mathbf{2 2 4 0 . 1}$ & $\mathbf{2 1 3 0 . 8}$ & $\mathbf{- 4 . 9}$ \\
3 & 2112.4 & 1836.3 & -13.1 \\
\hline
\end{tabular}

Table 4. Comparison of the effective damping $\left(\beta_{e f f}\right)$ obtained from Unified Mechanics Theory and test data

\begin{tabular}{cccc}
\hline \multirow{2}{*}{ Cycle } & \multicolumn{2}{c}{$\beta_{\text {eff }}$} & \\
\cline { 2 - 3 } & Test & Model & \\
\hline 1 & 0.249 & 0.323 & 29.9 \\
2 & $\mathbf{0 . 2 3 3}$ & $\mathbf{0 . 2 6 5}$ & $\mathbf{1 3 . 4}$ \\
3 & 0.211 & 0.193 & -8.4 \\
\hline
\end{tabular}

The amount of error of theoretical results can be measured in terms of energy dissipated per cycle $(E D C)$, effective stiffness $\left(K_{e f f}\right)$ and effective damping $\left(\beta_{\text {eff }}\right)$. Precisely, Tables 2 to 4 compare the respective values obtained from Unified Mechanics Theory simulations to the ones from laboratory test. The percentages of error confirmed that the second loop is the best represented.

Finally, it is possible to affirm that if all entropy generation mechanisms are included in the thermodynamic fundamental equation, material properties for high-purity lead are available, and large-strain formulation is used, the difference in EDC, $K_{\text {eff }}$ and $\beta_{\text {eff }}$ between test data and numerical simulations should be insignificant.

\section{Conclusions}

This study is the first attempt in the literature to use the Unified Mechanics Theory to simulate the 
mechanical behavior of lead-rubber bearings. Degradation effects were included in the analysis through the Thermodynamic State Index; i.e., it was not necessary to apply empirical curve fitting degradation functions. As a result, a good match between analytical and experimental forcedisplacement curve was obtained, particularly for the second hysteresis loop.

Precisely, the percentages of error in energy dissipated per cycle, effective stiffness and effective damping are $7.9,-4.9$ and $13.4 \%$, respectively, for that loop. This is mainly important because second loops are often used to calculate nominal mechanical properties of seismic isolators. Besides, the model based on Unified Mechanics Theory could capture the significant difference in EDC between first and second - and first and third - hysteresis loops.

Even though the modified small-strain formulation implemented in ABAQUS by a UMAT subroutine demonstrated efficiency for modelling LRB isolators as a first order approximation, error between simulations and test data is partly due to this shortcoming. Therefore, large-strain formulation should be included for a more precise finite element analysis. Other source of error is the use of material properties corresponding to eutectic $63 \mathrm{Sn} / 37 \mathrm{~Pb}$ solder alloys. Hence, it is necessary to obtain properties for high-purity lead $(99.99 \%)$. Likewise, considering all mechanisms of Eq. (4) in the calculation of the entropy generation rate would yield more accurate results.

\section{Declaration of conflicting interests}

The author(s) declared no potential conflicts of interest with respect to the research, authorship, and/or publication of this article.

\section{Acknowledgments}

My infinite gratitude to Dr. Cemal Basaran for allowing me to apply his theory, the Unified Mechanics, to do research in seismic isolation. This article is the result of both his expertise in damage mechanics and my interest in structural control. Likewise, special thanks are due to the Fulbright
Program and the School of Engineering and Applied Sciences at the University at Buffalo for the financial support of my master's program, during which I developed this work.

\section{References}

[1] Robinson WH (1982) Lead-rubber hysteretic bearings suitable for protecting structures during earthquakes. Earthquake Engineering and Structural Dynamics 10:593-604.

[2] SAP2000 (2007) Structural analysis and design. Computers \& Structures, Inc., Berkeley, CA, USA.

[3] Nagarajaiah S, Reinhorn AM, Constantinou MC (1991) 3D-BASIS: Nonlinear dynamic analysis of three dimensional base isolated structures - Part II. Technical Report NCEER-91-0005. National Center for Earthquake Engineering Research, State University of New York at Buffalo, NY, USA.

[4] Kikuchi M, Aiken ID (1997) An analytical hysteresis model for elastomeric seismic isolation bearings. Earthquake Engineering and Structural Dynamics 26(2):215-231.

[5] Constantinou MC, Whittaker AS, Kalpakidis IV, Fenz DM, Warn GP (2007) Performance of seismic isolation hardware under service and seismic loading. Technical Report MCEER-07-0012. Multidisciplinary Center for Earthquake Engineering Research, State University of New York at Buffalo, NY, USA.

[6] Kalpakidis IV, Constantinou MC (2008) Effects of heating and load history on the behavior of leadrubber bearings. Technical Report MCEER-080027. Multidisciplinary Center for Earthquake Engineering Research, State University of New York at Buffalo, NY, USA.

[7] Kalpakidis IV, Constantinou MC, Whittaker AS (2010) Modeling strength degradation in leadrubber bearings under earthquake shaking. Earthquake Engineering and Structural Dynamics 39:1533-1549.

[8] Wake T, Kikuchi M, Ishii K (2017) Strength degradation in lead-rubber bearings during a longduration earthquake. Proceedings of the New Zealand Society for Earthquake Engineering Annual Conference, Wellington, New Zealand.

[9] Basaran C (2021) Introduction to Unified Mechanics Theory with Applications. Springer Nature, ISBN 978-3-030-57771-1.

[10] Bin Jamal N, Kumar A, Rao L, Basaran C (2020) Low cycle fatigue life prediction using Unified 
Mechanics Theory in Ti-6Al-4V alloys. Entropy 22(1): 24.

[11] Egner W, Sulich P, Mrozinski S, Egner H (2020) Modeling thermo-mechanical cyclic behavior of P91 steel. International Journal of Plasticity 135:102820.

[12] Osara JA, Bryant MD (2019) Thermodynamics of fatigue: Degradation-entropy generation methodology for system and process characterization and failure analysis. Entropy 21(7):685.

[13] Young C, Subbarayan G (2019) Maximum entropy models for fatigue damage in metals with application to low-cycle fatigue of aluminum 2024T351. Entropy 21(10):967.

[14] Imanian A, Modarres M (2018) A thermodynamic entropy-based damage assessment with applications to prognosis and health management. Structural Health Monitoring 17(2):240-254.

[15] Wang J, Yao Y (2017) An entropy based low-cycle fatigue life prediction model for solder materials. Entropy 19:503

[16] Sosnovskiy LA, Sherbakov SS (2016) Mechanothermodynamic entropy and analysis of damage state of complex systems. Entropy 18:268.

[17] Temfack T, Basaran C (2015) Experimental verification of thermodynamic fatigue life prediction model using entropy as damage metric. Materials Science and Technology 31(13):16271632.

[18] Yao W, Basaran C (2013) Computational damage mechanics of electromigration and thermomigration. Journal of Applied Physics 114(10): 103708.

[19] Yao W, Basaran C (2013) Electromigration damage mechanics of lead-free solder joints under pulsed DC: A computational model. Computational Materials Science 71:76-88.

[20] Yao W, Basaran C (2012) Electromigration analysis of solder joints under ac load: A mean time to failure model. Journal of Applied Physics 111(6):063703.

[21] Lee Y, Basaran C (2011) A creep model for solder alloys. ASME Journal of Electronic Packaging 133(4):044501.

[22] Naderi M, Amiri M, Khonsari M M (2010) On the thermodynamic entropy of fatigue fracture. Proceedings of the Royal Society A: Mathematical, Physical and Engineering Sciences 466(2114):423438.
[23] Abdulhamid MF, Basaran C (2009) Influence of thermomigration on lead-free solder joint mechanical properties. ASME Journal of Electronic Packaging 131(1):011002.

[24] Basaran C, Nie S (2007) A thermodynamics-based damage mechanics model for particulate composites. International Journal of Solids and Structures 44(3-4):1099-1114.

[25] Gomez J, Basaran C (2006) Damage mechanics constitutive model for $\mathrm{Pb} / \mathrm{Sn}$ solder joints incorporating nonlinear kinematic hardening and rate dependent effects using a return mapping integration algorithm. Mechanics of Materials 38(7):585-598.

[26] Gomez J, Basaran C (2006) Nanoindentation of $\mathrm{Pb} / \mathrm{Sn}$ solder alloys; experimental and finite element simulation results. International Journal of Solids and Structures 43(6):1505-1527.

[27] Basaran C, Zhao Y, Tang H, Gomez J (2005) A damage-mechanics-based constitutive model for solder joints. ASME Journal of Electronic Packaging 127 (3):208-214.

[28] Basaran C, Nie S (2004) An irreversible thermodynamics theory for damage mechanics of solids. International Journal of Damage Mechanics 13: 205-223.

[29] Basaran C, Lin M, Ye H (2003) A thermodynamic model for electrical current induced damage. International Journal of Solids and Structures 40(26):7315-7327.

[30] Basaran C, Chandaroy R (2000) Using finite element analysis for simulation of reliability tests on solder joints in microelectronic packaging. Computers \& Structures 74(2):215-231.

[31] Basaran C, Chandaroy R (1998) Mechanics of $\mathrm{Pb} 40 / \mathrm{Sn} 60$ near-eutectic solder alloys subjected to vibrations. Applied Mathematical Modelling 22(8):601-627.

[32] Basaran C, Yan CY (1998) A thermodynamic framework for damage mechanics of solder joints. ASME Journal of Electronic Packaging 120:379384.

[33] Basaran C, Chandaroy R (1997) Finite element simulations of the temperature cyling tests. IEEE Transactions on Components, Packaging, and Manufacturing Technology: Part A 20(4):530-536.

[34] Hernández Morales HM (2018) Damage Mechanics Of Lead-Rubber Bearings Using the Unified Mechanics Theory. MSc Thesis. State University of New York at Buffalo. 
[35] Skinner RI, Robinson WH, McVerry GH (1993) An Introduction to Seismic Isolation. John Wiley \& Sons Ltd., West Sussex, England.

[36] Lemaitre J, Chaboche JL (1990) Mechanics of Solid Materials. Cambridge University Press, Cambridge, UK.

[37] DeGroot SR, Mazur P (1962) Non-Equilibrium Thermodynamics. North-Holland Publishing Company, Amsterdam, Netherlands.

[38] Chaboche JL (1989) Constitutive equations for cyclic plasticity and cyclic viscoplasticity. International Journal of Plasticity 5:247-302.

[39] Kashyap BP, Murty GS (1981) Experimental constitute relations for the high temperature deformation of a $\mathrm{Pb}-\mathrm{Sn}$ eutectic alloy. Material Science and Engineering 50:205-213.
[40] Naeim F, Kelly J (1999) Design of Seismic Isolated Structures. John Wiley \& Sons, Inc., New York, USA.

[41] Hofmann W (1970) Lead and Lead Alloys: Properties and Technology. Springer-Verlag, Berlin, Germany.

[42] Massachusetts Institute of Technology. CalculiX CrunchiX user's manual version 2.7 [Images], Cambridge, MA, USA, 2014.

http://web.mit.edu/calculix_v2.7/CalculiX/ccx_2.7 $/ \mathrm{doc} / \mathrm{ccx} /$

[43] Warn GP, Whittaker AS (2004) Performance estimates in seismically isolated bridge structures. Engineering Structures 26: 1261-1278. 